\title{
Effects of Voltage-Gated Calcium Channel Subunit Genes on Calcium Influx in Cultured C. elegans Mechanosensory Neurons
}

\author{
Christian Frøkjær-Jensen, ${ }^{1,2}$ Katie S. Kindt, ${ }^{1}$ Rex A. Kerr, ${ }^{1}$ Hiroshi Suzuki, ${ }^{1}$ \\ Katya Melnik-Martinez, ${ }^{1}$ Beate Gerstbreih, ${ }^{3}$ Monica Driscol, ${ }^{3}$ William R. Schafer ${ }^{1}$ \\ ${ }^{1}$ Division of Biology, University of California, San Diego, La Jolla, California 92093-0349 \\ ${ }^{2}$ Department of Medical Physiology, University of Copenhagen, Copenhagen, Denmark $2200 \mathrm{~N}$ \\ ${ }^{3}$ Department of Molecular Biology and Biochemistry, Rutgers, The State University of New Jersey, \\ Piscataway, New Jersey 08854
}

Received 8 September 2005; accepted 5 January 2006

\begin{abstract}
Voltage-gated calcium channels (VGCCs) serve as a critical link between electrical signaling and diverse cellular processes in neurons. We have exploited recent advances in genetically encoded calcium sensors and in culture techniques to investigate how the VGCC $\alpha_{1}$ subunit EGL-19 and $\alpha_{2} / \delta$ subunit UNC-36 affect the functional properties of $C$. elegans mechanosensory neurons. Using the protein-based optical indicator cameleon, we recorded calcium transients from cultured mechanosensory neurons in response to transient depolarization. We observed that in these cultured cells, calcium transients induced by extracellular potassium were significantly reduced by a reduction-of-function mutation in egl-19 and significantly reduced by L-type calcium channel inhibitors; thus, a main source of touch neuron calcium transients appeared to be influx of
\end{abstract}

extracellular calcium through L-type channels. Transients did not depend directly on intracellular calcium stores, although a store-independent 2-APB and gadolinium-sensitive calcium flux was detected. The transients were also significantly reduced by mutations in unc36, which encodes the main neuronal $\alpha_{2} / \delta$ subunit in C. elegans. Interestingly, while egl-19 mutations resulted in similar reductions in calcium influx at all stimulus strengths, unc-36 mutations preferentially affected responses to smaller depolarizations. These experiments suggest a central role for EGL-19 and UNC-36 in excitability and functional activity of the mechanosensory neurons. (c) 2006 Wiley Periodicals, Inc. J Neurobiol 66: 000-000, 2006 Keywords: C. elegans; calcium channel; mechanosensation; neuroimaging; genetics
Correspondence to: W. R. Schafer (wschafer@ucsd.edu)

Contract grant sponsor: National Institute of Drug Abuse; contract grant number: R01 DA016445.

Contract grant sponsor: Human Frontier Science Program (W.R.S.).

(C) 2006 Wiley Periodicals, Inc.

Published online in Wiley InterScience (www.interscience.wiley. com).

DOI 10.1002/neu.20261

\section{INTRODUCTION}

Voltage-gated calcium channels (VGCCs) are ionic channels that mediate an influx of extracellular calcium in response to membrane depolarization. In excitable cells, entering calcium triggers neurotransmitter release from nerve terminals and muscle contraction through excitation-contraction coupling; in addition, calcium can act 
through second messengers to initiate longer lasting effects on gene expression and synaptic plasticity. Thus, VGCCs serve as an important link between electrical signaling and many important cellular processes in the nervous system (for a review see Catterall, 2000). In addition, because mutations in VGCC genes have been implicated in epilepsy, these channels represent a potentially important focus for the treatment of neurological disease in humans.

Vertebrate VGCCs typically consist of the poreforming $\alpha_{1}$ subunit and the accessory subunits $\beta, \alpha_{2} /$ $\delta$, and $\gamma$. The $\alpha_{1}$ subunit is a membrane spanning protein with a pore-forming structure in the center, which, when open, selectively allows $\mathrm{Ca}^{2+}$ ion flux across the membrane. The pore-forming subunit is composed of four repeated domains (I-IV), each consisting of six transmembrane segments (S1-S6). The S4 segment has regularly spaced positive amino acids, allowing the segment to function as a membrane voltage sensor. Each domain contains a membrane-associated loop with a pair of glutamate residues that confer the calcium ion specificity (Catterall, 2000). Vertebrate $\alpha_{1}$ subunits are classified into three major types: Ltype high voltage activated (HVA), non-L-type HVA, and low voltage activated (LVA), or T-type channels. L-type channels are HVA channels that are specifically blocked by dihydropyridines, phenylalkylamines, and benzothiazepines (Striessnig et al., 1998; Hockerman et al., 2000), and inactivate very slowly ( $\tau>500 \mathrm{~ms}$ ) relative to the faster LVA and non-L-type channels ( $\tau \approx 50 \mathrm{~ms}$ ) (Hille, 2001). HVA channels that are not blocked by dihydropyridines are classified as non-Ltype; these channels can be further classified into N-, $\mathrm{P} / \mathrm{Q}-$, and R-type based on differential blockade by peptide toxins.

The accessory subunits of VGCCs are not strictly necessary for channel function, but can modulate expression levels and channel properties (Singer et al., 1991; Catterall, 2000). The $\beta$ subunit is intracellular with no transmembrane segments. In contrast, the $\gamma$ subunit spans the membrane and has been implicated in enhancing steady state channel inactivation in mice (Letts et al., 1998). The $\alpha_{2}$ subunit is located extracellularly, and is heavily glycosylated and tethered to the membrane by disulfide bonds to the membrane-spanning $\delta$ subunit (the $\alpha_{2}$ and $\delta$ subunits are encoded by the same gene, which undergoes post-translational cleavage and relinking by disulphide bonds; Jay et al., 1991). It is well established that $\alpha_{2} \delta$ subunits enhance $\alpha_{1}$ membrane expression and modulate the channel's biophysical properties (reviewed in Klugbauer et al., 2003). Although calcium channel accessory subunits affect expression level, single channel conductance, and activation/inactivation parameters in heterologously-expressed channels, the importance of these molecules for the normal function of VGCCs in vivo is less wellunderstood.

One way these questions have been addressed genetically is through analysis of calcium channel mutants in model organisms such as the nematode Caenorhabditis elegans. C. elegans has homologues of all the major types of VGCCs and the associated subunits. The $C$. elegans genome contains three genes with similarity to known vertebrate VGCCs. EGL-19, UNC-2, and CCA-1, encode L-type, non-L-type, and LVA T-type channels, respectively (Lee et al., 1997; Schafer and Kenyon, 1995; Mathews et al., 2003; Steger et al., 2005). Two additional genes (NCA-1 and NCA-2) resemble VGCCs with a similar four domain structure, but neither the genetic phenotypes nor the functional roles of these two putative channels have been reported. The functional role of VGCCs in C. elegans is especially interesting because of the apparent lack of voltage-gated $\mathrm{Na}^{+}$channels, which play an important role in action potential initiation in vertebrates. $C$. elegans neurons have a high input resistance and display a regenerative calcium current leading to a high sensitivity to sensory or synaptic input (Goodman et al., 1998). This suggests that C. elegans neurons are nonspiking and communicate by graded potentials (Thomas and Lockery, 1999); however, it is also possible that calcium-mediated action potentials could contribute to transmission of electrical signals down neuronal processes. C. elegans electrophysiology is technically challenging and the voltage-gated calcium currents in C. elegans cells have only been described in detail for body wall muscle (Jospin et al., 2002) and pharyngeal muscle (Shtonda and Avery, 2005). The effect of mutations in putative calcium channels and subunits on neuronal calcium currents has so far only been studied in vivo in response to mechanical stimulation (Suzuki et al., 2003), where pharmacological access and direct depolarization are limited.

In this study, we have analyzed the role of the VGCCs EGL-19 and UNC-36 in the calcium dynamics of $C$. elegans mechanosensory neurons. Using recently developed methods in primary cell culture and in vivo optical imaging, we have identified an important role for EGL-19 L-type calcium channels in the generation of depolarization-induced calcium transients in the cell bodies of cultured touch neurons. In addition, we have demonstrated that the UNC-36 accessory subunit strongly affects the magnitude and voltage-dependence of these neuronal calcium transients. 


\section{METHODS}

\section{Strain Handling}

Nematode strains were maintained at room temperature on standard nematode growth medium (NGM) seeded with Escherichia coli strain OP50 as food source. In order to collect eggs for primary cultures, nematodes were grown in larger scale at room temperature on enriched peptone plates seeded with $E$. coli strain NA22. All cameleon experiments were done on the integrated line bzIs18 (Suzuki et al., 2002), expressing YC2.12 under the control of the promoter mec-4.

\section{C. elegans Primary Cultures}

C. elegans primary cultures were prepared from synchronized worms as described by Christensen et al. (2002). Briefly, young gravid adults were treated with a $0.5 \mathrm{M} \mathrm{NaOH}$ and $1 \%$ $\mathrm{NaOCl}$ solution for $5 \mathrm{~min}$ to release eggs. After several washes with egg buffer (118 $\mathrm{mM} \mathrm{NaCl}, 48 \mathrm{mM} \mathrm{KCl}, 2 \mathrm{~m} M$ $\mathrm{CaCl}_{2}, 2 \mathrm{mM} \mathrm{MgCl}$, and $25 \mathrm{~m} M$ HEPES, pH 7.3, $340 \mathrm{mOsm}$ ), eggs were isolated from adult carcasses by centrifugation in a $30 \%$ sucrose gradient. The isolated eggs were resuspended in a small volume of sterile water and added to $0.5 \mathrm{~mL} \mathrm{egg}$ buffer containing nominally $1 \mathrm{U} / \mathrm{mL}$ chitinase (Sigma Chemical, St. Louis, MO) to digest the eggshell. Eggs were digested 15-20 min on a turning rack and washed once with culturing medium L-15 (Life Technologies, Grand Island, NY) containing 10\% fetal bovine serum (Life Technologies), $50 \mathrm{U} / \mathrm{mL}$ penicillin, $50 \mu \mathrm{g} / \mathrm{mL}$ streptomycin and osmolarity of $340 \mathrm{mOsm}$. Eggs were dissociated by pipetting the solution up and down in an Eppendorf tube with a $1 \mathrm{~mL}$ pipettor. When a satisfactory degree of dissociation had been achieved, the cells were pelleted and resuspended in fresh L-15 solution. Single cells were isolated from undissociated eggs and clumps of cells by filtration through a $5 \mu \mathrm{m}$ Durapore filter (Millipore, Bedford, MA). The single dissociated cells were washed once in L-15 and plated at a concentration of $2.5 \times 10^{4}$ cells $/ \mu \mathrm{L}$ on $\mathrm{UV}$-sterilized $12 \mathrm{~mm}$ acid washed cover glass (Fisher Scientific, Pittsburgh, PA) coated with $1 \mathrm{mg} / \mathrm{mL}$ peanut lectin (Sigma). Cells were cultured in 24-well Costar culture plates (Corning Inc., Corning, NY) and left for $2 \mathrm{~h}$ on cover glass to adhere before filling the well with L-15 growth medium. Cells were grown in plastic boxes containing wet tissues in a $25^{\circ} \mathrm{C}$ incubator. All culturing was carried out on a lab bench using sterile techniques.

\section{Optical Imaging}

Cultured Cells. Two- to three-day-old cells were placed in a RC-26 GLP open recording chamber (Warner Instrument Corp., Hamden, CT) and attached to the bottom of the well with vacuum grease. Cells were perfused with an extracellular saline solution $(145 \mathrm{mM} \mathrm{NaCl}, 5 \mathrm{~m} M \mathrm{KCl}, 2 \mathrm{~m} M$ $\mathrm{CaCl}_{2}, 1 \mathrm{~m} M \mathrm{MgCl}_{2}, 10 \mathrm{~m} M$ HEPES, $10 \mathrm{~m} M$ D-glucose, $\mathrm{pH} 7.2$ and $340 \mathrm{mOsm}$ ) to remove culture medium and nonadherent cells. Optical recordings were done on a Zeiss Axioscope 2 upright compound microscope with a Hama- matsu Orca ER II CCD camera, a Hamamatsu W-view emission image splitter, and a Uniblitz Shutter (Vincent Associates). Recordings were done on a $1200 \mathrm{MHz}$ Athlon (Advanced Micro Devices) computer with the program MetaVue 4.6 (Universal Imaging Corp., Downingtown, PA) running Windows 98 (Microsoft). Images were acquired at $10 \mathrm{~Hz}$ (100 ms exposure time) with $4 \times 4$ binning, using a 63X Zeiss Achroplan water immersion objective. Filter/ dichroic pairs were: excitation, 420/40; excitation dichroic, 455; CFP emission, 480/30; emission dichroic, 505; YFP emission, 535/30 (Chroma). Healthy looking cameleonexpressing neurons were located by eye under minimal fluorescence to minimize photobleaching. Before starting the recording, cells were perfused with extracellular solution for $5 \mathrm{~s}$ to stabilize the solution level in the recording chamber. The recording protocol consisted of 3-5 s extracellular saline perfusion, $8 \mathrm{~s}$ high $\mathrm{K}^{+}$solution, and $12-14 \mathrm{~s}$ extracellular saline. The high $\mathrm{K}^{+}$solution was a modified version of the extracellular saline solution with variable amounts of $\mathrm{KCl}$ substituted for $\mathrm{NaCl}$. The solutions were delivered with a gravity feed perfusion system, with six solution tubes reaching a manifold (Warner Instruments) and one tube entering the recording chamber with a flow rate of approximately $0.5 \mathrm{~mL} / \mathrm{s}$.

Data Analysis. Stacks of images were acquired with MetaVue (Universal Imaging) and saved to a computer hard drive. A custom written Java-based program (Kerr et al., 2000; Suzuki et al., 2003) was used to define regions of interest. The program automatically tracked these regions and reported the total CFP and YFP intensity for each frame.

The separation of the YFP and CFP emission with filters was not perfect. We measured the crosstalk between the two channels with purified CFP or YFP protein. The correction parameters for crosstalk between the CFP and the YFP channel were measured to be: YFP emission crosstalk $\mathrm{Ca}$ / $D a=0.01$, CFP emission crosstalk $C d / D d=0.60$, where $D d$ and $D a$ are the detector quantum efficiencies through the correct channel and $C d$ and $C a$ are the detector quantum efficiencies through the wrong channel. Given the relative small size of $C a / D a$ only the $C d / D d$ crosstalk was corrected for, effectively subtracting $60 \%$ of the CFP intensity from the YFP intensity.

Ratios were further analyzed and plotted for visual inspection using custom written analysis scripts in MATLAB R12 (The Mathworks). The ratio trace was low-pass filtered with a Gaussian blur of the form $e^{-(\mathrm{X} / \sigma)^{2}}$. Events were detected as $N$ of $M$ successive frames displaying an increase corresponding to a slope of at least $s$. The parameters $N, M$, and $s$ varied slightly between different experiments to give satisfactory event detection as judged by eye. The blur was kept constant at $\sigma=8$ for $\mathrm{K}^{+}$-induced transients to prevent skewing of data.

Drugs. All drugs were purchased from Sigma. Solutions were made from at least $500 \mathrm{X}$ stock solutions in either DMSO or $\mathrm{dH}_{2} \mathrm{O}$. 


\section{Potassium Dose-Response Tests}

We depolarized the cultured neurons transiently with an extracellular solution containing a high concentration of $\mathrm{K}^{+}$. The protocol had previously been used with success under similar conditions to characterize the effect of drugs that bind to the $\alpha_{2} / \delta$ subunit in rat (Martin et al., 2001; Sutton et al., 2002). We used $\mathrm{K}^{+}$-concentrations of 20, 40, 60, 80 , and $100 \mathrm{~m} M$ corresponding to changes in reversal potential of $34,51,62,69$, and $75 \mathrm{mV}$, respectively. We perfused cultured neurons for $8 \mathrm{~s}$ with the extracellular solution containing a high concentration of $\mathrm{K}^{+}$to determine the cameleon ratio change. Perfusion with $\mathrm{K}^{+}$did not change the focal plane or disturb the position of the neurons. Bleaching was minimized by using neutral density filters to limit the intensity of the excitation light; multiple $25 \mathrm{~s}$ recordings of a sample were possible without loss of indicator intensity. At low $\mathrm{K}^{+}$concentrations, such as 20 and $40 \mathrm{~m} M$, there were a large number of nonresponsive cells. For $100 \mathrm{mM} \mathrm{K} \mathrm{K}^{+}$depolarization only 3 out of 307 cells did not respond. For all experiments with 20, 40, and $60 \mathrm{mM} \mathrm{K} \mathrm{K}^{+}$concentrations, initially nonresponsive cells that did respond to a subsequent $100 \mathrm{~m} M \mathrm{~K}^{+}$were discarded from the experiments. Most frequently, cells that did not respond to low $\mathrm{K}^{+}$concentrations would respond normally to $100 \mathrm{mM} \mathrm{K}^{+}$concentrations [e.g., 13/13 cells nonresponsive at $40 \mathrm{~m} M$ responded to $100 \mathrm{~m} M$; see Fig. 3(C) legend].

\section{Molecular Biology}

Sequence alignment was done by aligning the EGL-19 cDNA sequence and the rat brain $\alpha_{1}$ L-type calcium channel (Genbank accession number \#M67515; Snutch et al., 1991) with the alignment tool available at NCBI http:// www.ncbi.nlm.nih.gov/blast/bl2seq/wblast2.cgi.

An unc-36 promoter GFP fusion was constructed by amplifying a $1.7 \mathrm{~kb}$ promoter region by PCR from genomic DNA with the primers $5^{\prime}$-GGATCCGATTTGTTTGTTGCGCGCCGG-3' and 5'-ACCGGTGATGAACCACTCGCTTTCTCG-3' corresponding to 1687 bps upstream of the translation start site. The second primer overlaps with the translation start and has a deliberate missense mutation to change the start codon. The PCR product was inserted into a topo TA vector. BamH I and Age I restriction enzymes were used to circularize the Fire lab vector pPD95.79 and to cut out the topo-TA-PCR product; PCR product and pPD95.79 were ligated and used to transform competent bacteria. The purified promoter GFP construct was coinjected with $d p y-20(+)$ gene into $d p y$-20(e1282ts) following the protocol in Mello and Fire (1995) to obtain strains propagating the plasmid as an extrachromosomal array.

The length of the promoter was chosen so that it did not overlap with the adjacent $s n b-5$ gene located $2.0 \mathrm{~kb}$ upstream. The $1.7 \mathrm{~kb}$ fragment was amplified by PCR from genomic DNA and inserted into a TopoTA vector. The TopoTA plasmid was amplified in competent bacteria, digested with the restriction enzymes BamHI and AgeI, and isolated from an $1 \%$ agarose gel after electrophoresis. The fragment was ligated into a cut Fire lab vector pPD95.79 containing GFP in an open reading frame. Competent bacteria were transformed with the ligation mixture and antibiotic resistant colonies were selected. The construct was verified with several restriction enzyme digests. Plasmid was reisolated with a midi-prep to get sufficient purity for injection. The plasmid was coinjected with $d p y-20(+)$ gene into the gonad of young $d p y$-20(e1282ts) hermaphrodites. After a couple of days nonmutant progeny were isolated from the injected animals and these strains were monitored for transgene propagation to progeny. Several independent transgenic lines were obtained and all showed similar, bright GFP expression.

The T24F1.6 promoter GFP fusion was prepared by PCR fusion, following the protocol of Hobert (2002). The T24F1.6 promoter GFP fusion was amplified with upstream primers 5'-GGATCCGAAATTCTATTCATTCTTCTCATCTCAAAACCC $-3^{\prime}$ and 5'-CCCTCAATTTGATCCCTCTCCTC $-3^{\prime}$, corresponding to 1385 and 1354 bp upstream of the translation start. The PCR overlap primers were $5^{\prime}$ CTAGAGTCGACCTGCAAGGCGGTCATTGTTGAAGTATTTCG- $3^{\prime}$ and $5^{\prime}-$ CGAAATACTTCAACAATGACCGCCTTGCAGGTCGACTCTAG- ${ }^{\prime}$, and the two GFP primers were $5^{\prime}$-AAGGGCCCGTACGGCCGACTAGTAGG-3' and 5'- GGAAACAGTTATGTTTGGTATATTGGG - 3' .

Promoter T24F1.6 DNA was amplified from genomic DNA and the GFP from Fire lab vector pPD95.75 by PCR with the Expand Long Template PCR System (Roche). Gel extracted DNA was coinjected with lin-15(+) gene into lin$15(n 765 t s)$ and lines stably transmitting the injected DNA were obtained.

\section{Statistics}

Statistical analysis of pharmacological and genetic data was performed using a one- way ANOVA. If means were significantly different then Dunnett's multiple comparison posthoc test was used to test statistical difference from wildtype controls. In some cases individual posthoc $t$ test comparisons were performed between two drugs (i.e., nifedipine vs. nifedipine +2 -APB) or two drug concentrations (i.e., $1 \mu M$ Nif vs. $10 \mu M$ Nif).

\section{Pharmacological Experiments}

The cells were initially stimulated with $100 \mathrm{mM} \mathrm{K} \mathrm{K}^{+}$in the absence of drug. After the first stimulation cells were flushed with extracellular saline containing the drug. Two minutes later the cells were stimulated with $100 \mathrm{mM} \mathrm{\textrm {K } ^ { + }}$ solution, also containing the drug. Cells were washed several times with extracellular saline and after another 2 min wait were stimulated a third time with $100 \mathrm{mM} \mathrm{K} \mathrm{K}^{+}$, to test for the reversibility of drug action. Drug activity was measured by normalizing second stimulus amplitude to first stimulus amplitude. These normalized amplitudes were compared to normalized amplitudes from control cells without drugs applied. A maximum of three stimulations and one drug was used on a plate of cells. 


\section{Quantitation of Touch Responses}

We touched 20 worms 10 times each, alternating anterior and posterior gentle touch with an eyelash hair at approximately $1 \mathrm{~s}$ intervals. We recorded the percentage of total responses, averaged for three independent trials.

\section{Scoring Touch Neuron Positions}

Nematodes were mounted on $2 \%$ agarose pads with $40 \mathrm{mM}$ $\mathrm{NaN}_{3}$ for anesthesia. The positions of AVM and ALM were determined using Nomarski optics at the end of L1 and early L2 stage. At this stage the hypodermal V cells have divided once and are stationary markers that can be used to score the positions of the neuron cell bodies. The positions of AVM and ALM axons were visualized by fluorescence microscopy in L4 worms carrying the mec-4::GFP array.

\section{RESULTS}

\section{Cultured C. elegans Mechanosensory Neurons Retain Functional Properties of Touch Neurons}

To investigate the role of calcium channel subunits in neuronal function, we chose to use the mechanosensory neurons. We have previously shown that cultured touch neurons retain several key aspects of their in vivo physiological and cell biological properties such as neuron morphology, cytoskeletal structures, and necrosis of mec-4(u231) ((mec-4(d)) neurons (Bianchi et al., 2004). Furthermore, calcium transients and their dependence on VGCC channel subunits have been characterized in vivo during gentle and harsh touch stimulation (Suzuki et al., 2003). Also, in an impressive recent study in vivo mechanosensory transduction channels were characterized electrophysiologically (O'Hagan et al., 2004). However, the role of VGCCs and intracellular stores in the response to depolarization of the plasma membrane in neurons has not been studied. We prepared C. elegans primary cultures (Christensen et al., 2002) from a strain expressing a high-affinity version of cameleon (yellow cameleon version 2.12; YC2.12) in the mechanosensory neurons. Cameleon expression restricted to the mechanosensory neurons was confirmed by fluorescent microscopy. In culture, muscle and neuronal cells were clearly identifiable within $24 \mathrm{~h}$ after plating and a subset of the neurons expressed the cameleon protein. When we characterized the dynamic properties of the cameleon YC2.12 sensor in cultured neurons, important properties such as the dynamic range and free $\mathrm{Ca}^{2+}$ sensitivity agreed with in vitro characteristics of the sensor (Bianchi et al., 2004; Miyawaki et al., 1999). In low calcium, the cyan fluo- rescent protein (CFP) emission and yellow fluorescent protein (YFP) emission were nearly equal [Fig. 1(A)]. When the calcium concentration increased the emission shifted to YFP at the expense of CFP, resulting in a higher YFP/CFP ratio.

\section{Response Properties of YC2.12 in Cultured Mechanosensory Neurons}

To study the function of VGCCs we measured intracellular changes in calcium concentration evoked by excitation of cultured neurons. We transiently depolarized the cultured touch neurons with high concentrations of extracellular potassium and measured the YFP and CFP emissions in the cell body, looking for YFP/CFP ratio changes indicative of changes in calcium concentration. Figure 1(B) shows the response of a neuronal cell body stimulated with $100 \mathrm{mM} \mathrm{K} \mathrm{K}^{+}$. As expected, depolarizing the neuron resulted in reciprocal changes in YFP and CFP emission. The YFP/CFP ratio, displayed below the individual intensities, is the most relevant indication of a transient change in intracellular calcium level. The YFP/CFP ratio is less dependent on indicator concentration and is robust against artifacts caused by movement and lamp instability (Kerr et al., 2000). Calcium transient magnitude was dependent on the strength of the depolarizing stimulus (i.e., the $\mathrm{K}^{+}$concentration). $\mathrm{K}^{+}$ $(100 \mathrm{~m} M)$ induced ratio changes of $67 \pm 1 \%(n$ =34), whereas $60 \mathrm{~m} M \mathrm{~K}^{+}$and $40 \mathrm{~m} M \mathrm{~K}^{+}$resulted in ratio changes of $45 \pm 4 \%(n=11)$ and $36 \pm 2 \%(n$ $=12$ ), respectively [Fig. 1(C)]. Cells stimulated with 40 and $20 \mathrm{mM} \mathrm{K} \mathrm{K}^{+}$also exhibited a significantly higher rate of response failures (13/102 and 25/31, respectively) than cells stimulated with higher concentrations. Thus the cells showed a concentration-dependent calcium response to a depolarizing stimulus of extracellular potassium, suggesting the involvement of voltage-dependent calcium channels. Changes in flow-rate that visibly perturbed cells mechanically did not elicit ratio changes, suggesting that normal touch sensitivity was not present in cultured cells (data not shown).

To further characterize the source of calcium transients we repeatedly stimulated cells with $100 \mathrm{~m} M$ $\mathrm{K}^{+}$in the presence of a range of extracellular calcium concentrations. Calcium transients were completely abolished in the absence of extracellular $\mathrm{Ca}^{2+}$ [Fig. 1(D)]. Transients could be restored to comparable amplitudes with $0.5,1$, and $2 \mathrm{mM} \mathrm{Ca}^{2+}$ in the extracellular solution. The relative independence of calcium flux and extracellular calcium concentration was not surprising because VGCC flux typically is limited by the number of $\mathrm{Ca}^{2+}$ ions that can flow through the pore and not by diffusion (Hille, 2003). However, the requirement for extracellular calcium for transients suggested that 

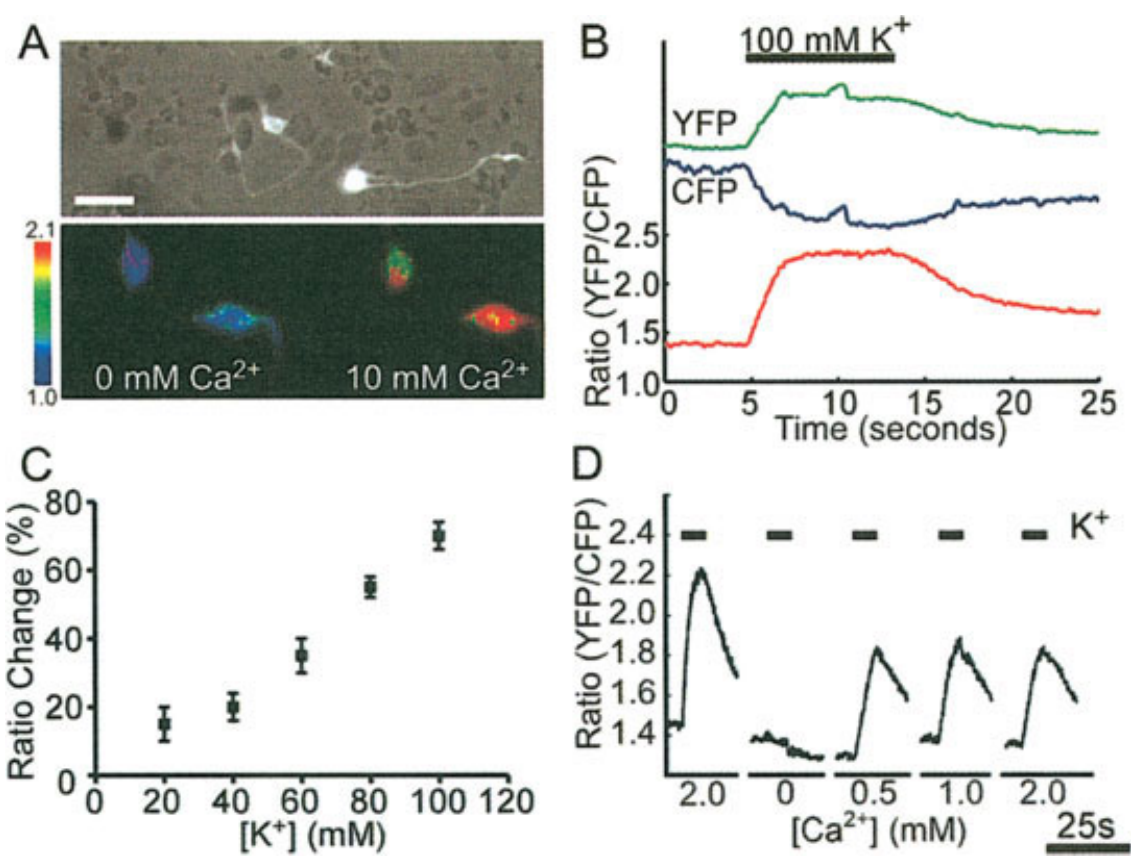

Figure 1 Cellular identity of cultured mechanosensory neurons. (A) Top. Primary C. elegans culture of the strain bzIs18, which expresses yellow cameleon 2.12 (YC2.12) in the mechanosensory neurons. Cameleon expression increased during the first 2 days in culture and lasted for 2 weeks, though most experiments were performed after 3 days of culture. The picture was taken 3 days after culturing and shows differentiated neurons expressing cameleon protein (bright neurons). White scale bar $=10 \mu \mathrm{m}$. Bottom. Pseudo color image of cultured mechanosensory neurons in low calcium (0 $\mathrm{m} M \mathrm{Ca}^{2+}, 5 \mathrm{~m} M$ EGTA), left, and high calcium $\left(10 \mathrm{~m} M \mathrm{Ca}^{2+}\right)$, right. Pseudo color scale bar indicates the yellow fluorescent protein/cyan fluorescent protein (YFP/CFP) emission ratio. (B) Calcium imaging of cultured mechanosensory neuron. The top traces show the individual YFP and CFP intensities and the bottom trace the ratio YFP/CFP. The ratio faithfully records the reciprocal change in the individual intensities. Spikes in YFP and CFP intensities (such as the one at $t=10 \mathrm{~s}$ ) reflect lamp instability and are effectively canceled out in the ratio. (C) Transient amplitude dependence on $\mathrm{K}^{+}$concentration in the extracellular solution. When stimulated with low concentrations of $\mathrm{K}^{+}$many cells did not respond. Stimulation with 40 and $20 \mathrm{mM} \mathrm{K} \mathrm{K}^{+}$yielded 13/102 and $25 / 31$ nonresponsive cells, respectively, whereas stimulation with 100 and $60 \mathrm{~m} M \mathrm{~K}^{+}$resulted in only $3 / 307$ and 1/47 nonresponsive neurons, respectively. All 13 neurons that did not respond to $40 \mathrm{~m} M$ $\mathrm{K}^{+}$responded to subsequent stimulation with $100 \mathrm{~m} M \mathrm{~K}^{+}$. All nonresponsive cells were excluded from further analysis. (D) Transient amplitude dependence on extracellular calcium. Each successive stimulation with $100 \mathrm{mM} \mathrm{K} \mathrm{K}^{+}$was separated by $2 \mathrm{~min}$ and carried out with the $\mathrm{Ca}^{2+}$ concentration indicated in bath and in high $\mathrm{K}^{+}$solution. Removing extracellular calcium reproducibly abolished transients [amplitude $\left(0 \mathrm{mMCa} \mathrm{Ca}^{2+}\right)=0 \pm 0 \%(n=5)$, amplitude (control) $=58 \pm 1 \%(n=12)$ ].

calcium entering the cell through VGCCs is necessary to trigger the cell's calcium response to depolarization.

Evanko and Haydon (2005) showed that the response properties of YC6.1, a newer version of the yellow cameleon calcium sensor (Truong et al., 2001), are very dependent on resting YFP/CFP ratio and sensor expression level. To determine the effect of baseline YFP/CFP ratio and indicator expression level in cell cultures, we tested the response properties of YC2.12 (Fig. 2). We found that the resting YFP/CFP ratio in cultured mechanosensory neurons was distributed around a YFP/CFP ratio of $1.4 \pm 0.3$ (average $\pm \mathrm{SD}$ ). We analyzed the transient amplitude as a function of baseline ratio and indicator expression level, measured by the intensity of CFP fluorescence [Fig. 2(B,C)]. The ratio change was only weakly negatively correlated with baseline YFP/CFP ratio $\left(R^{2}=0.06, p<0.01\right)$, which contrasts with the positive linear correlation Evanko and Haydon (2005) reported for YC6.1. We could not detect any statistically significant correlation between sensor expression level and ratio change, consistent with data measured from the closely related sensor YC2.3 expressed in fruit flies (Reiff et al., 2005). Evanko and Haydon (2005) also reported that the baseline ratio of YC6.1 was dependent on sensor expression level rather than 

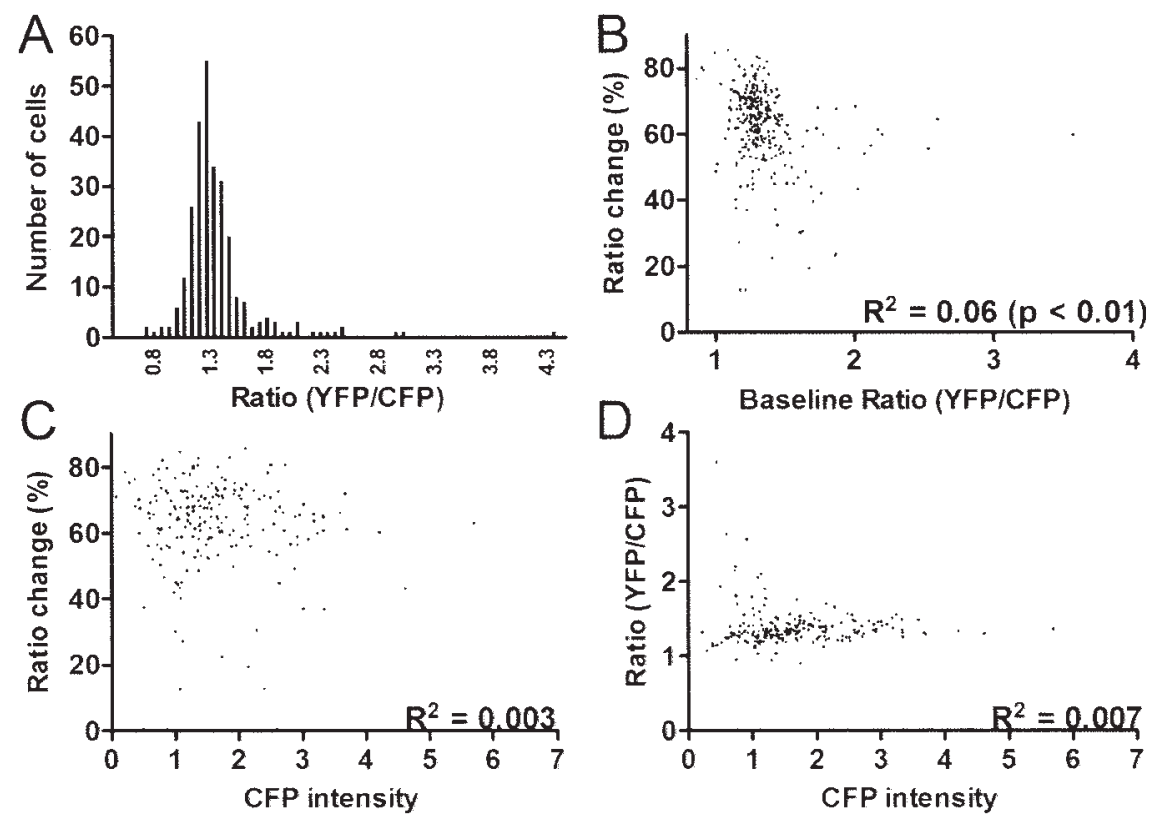

Figure 2 Responsiveness of YC2.12 and resting ratio value. (A) Histogram showing the resting, prestimulus YFP/CFP ratio value of 275 cultured wild-type neurons. (B) Relationship between prestimulus YFP/CFP ratio and response to stimulation with $100 \mathrm{~m} M$ extracellular $\mathrm{K}^{+}$. There is a weak correlation between YFP/CFP ratio and response, with higher YFP/CFP ratio giving slightly smaller responses. Pearson correlation coefficient $R^{2}=0.06, p<0.01$. (C) Relationship between YC2.12 expression level (quantified by intensity of CFP signal) and ratio change. In the range of expression levels we observed in cultured mechanosensory neurons there was no significant correlation between indicator expression level and responsiveness (Pearson $R^{2}=0.003, p>0.05$ ). (D) Relationship between YC2.12 expression level and resting YFP/CFP ratio. No significant correlation is observed (Pearson $R^{2}=0.007, p>0.05$ ).

baseline calcium concentration. We have previously used an in situ calibration of YC2.12 and the baseline YFP/CFP ratio level to estimate the resting free intracellular calcium concentration in cultured mechanosensory neurons to be on the order of $200 \mathrm{n} M$ (Bianchi et al., 2004). We could not detect any correlation between expression level and baseline ratio value [Fig. 2(D)]. We conclude that the response properties of $\mathrm{YC} 2.12$ are robust in the range of concentrations encountered in cultured mechanosensory neurons.

\section{Calcium Transients in Cultured Touch Neurons Depend on EGL-19/L-Type Channels}

To address the molecular identity of the calcium-conducting channels in cultured touch neurons, we characterized the effects of calcium channel mutations and pharmacological blockers on calcium transients (Figs. 3 and 4). Because pharmacological blockers of calcium channels (and other ion channels) have not been extensively tested electrophysiologically on invertebrates interpretation must necessarily be cautious.
Where possible, we used drugs characterized electrophysiologically on C. elegans muscle (Jospin et al., 2002; Shtonda and Avery, 2005). We first assayed the effect of $\mathrm{Gd}^{3+}(1 \mu M)$, a broad spectrum blocker of VGCCs (Biagi and Enyeart, 1990; Bleakman et al., 1995), store-operated calcium channels (SOCs) (Putney, 2001), and, at higher concentrations, mechanosensory channels (Yang and Sachs, 1989; Kimitsuki et al., 1996) and ryanodine receptors (Sarközi et al., 2005). As shown in Figure 3(A), $1 \mu M \mathrm{Gd}^{3+}$ resulted in a complete and reversible block of depolarizationinduced calcium influx. We also tested the effect of $\mathrm{Ni}^{2+}$, which can act as either a general VGCC blocker (at high concentrations) or as a selective T-type VGCC blocker (at low concentrations) for one of the mammalian T-type channels (Ertel et al., 1997; Lee et al., 1999; Zamponi et al., 1996). We tested $\mathrm{Ni}^{2+}$ at low concentrations $(20 \mu M)$ and high concentrations $(1 \mathrm{mM})$. The low concentration had a modest but significant effect on the calcium transients whereas the high concentration strongly reduced calcium transients.

In pharyngeal muscle L-type (EGL-19) and T-type (CCA-1) are equally sensitive to nickel with effects 


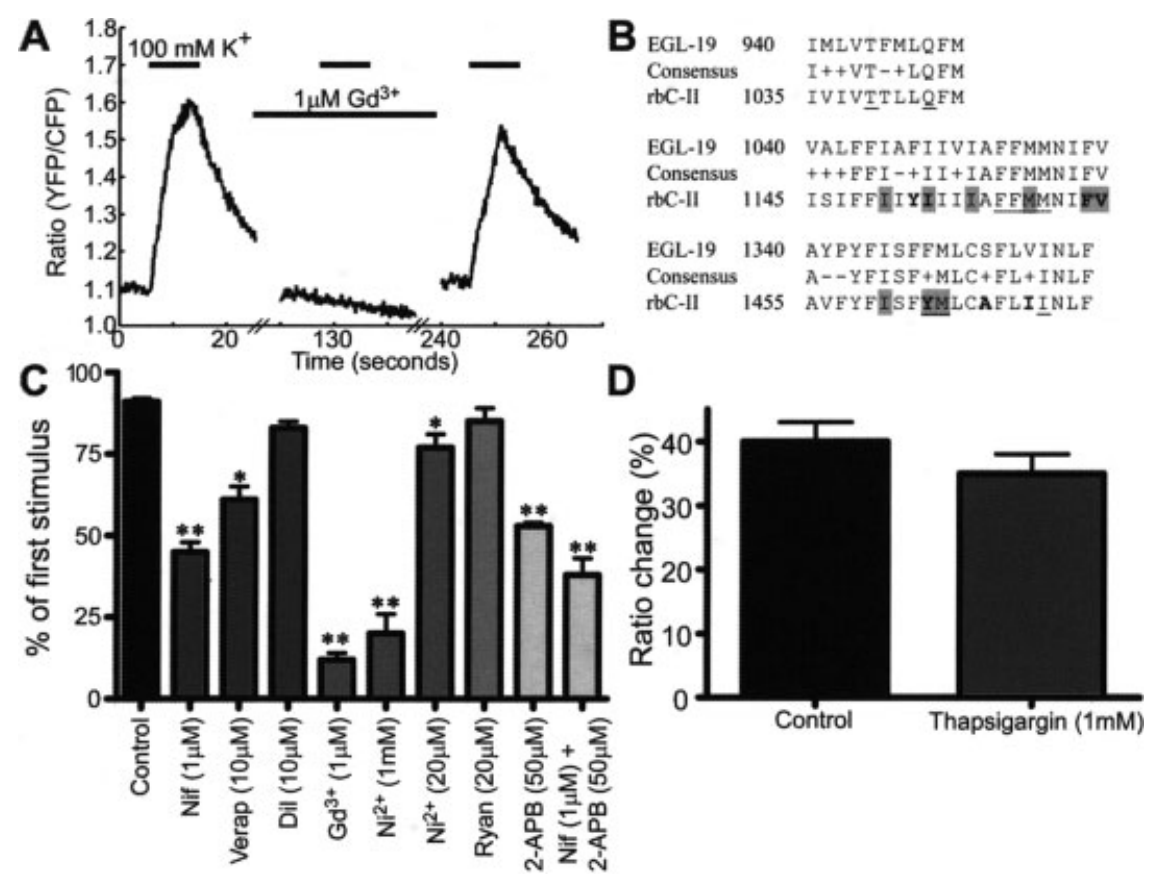

Figure 3 Wild-type pharmacology. (A) Wild-type cultures stimulated with $100 \mathrm{mM} \mathrm{\textrm {K } ^ { + }}$ without drug, then in the presence of $1 \mathrm{~m} M \mathrm{Gd}^{3+}$, and finally after washout of drug. Cells were incubated approximately 2 min with drug before the second depolarization and drug was included in both bath solution and depolarizing $\mathrm{K}^{+}$solution. The drug reversibly reduced the amplitude of the calcium transient in response to depolarization. (B) Alignment of regions involved in drug binding. Schematic showing parts of the aligned rat $\alpha_{1}$ L-type calcium channel (Snutch et al., 1991) and EGL-19 amino acid sequence. Underlined residues indicate putative role in dihydropyridine (i.e., nifedipine) sensitivity (Striessnig et al., 1998), bold residues are involved in phenylalkamine (i.e., verapamil) sensitivity (Hockerman et al., 2000), and gray colored residues are involved in benzothiazepine (i.e., verapamil) binding (Striessnig et al., 1998). Consensus strand based on identity, similarity (+) or no similarity (-). (C) Calcium transient amplitude in response to $100 \mathrm{mM} \mathrm{K} \mathrm{K}^{+}$in the presence of L-type channel blockers nifedipine (Nif), verapamil (Verap), and diltiazem (Dil), unspecific VGCC and store-operated channel blocker gadolinium $\left(\mathrm{Gd}^{3+}\right)$ and unspecific VGCC channel blocker nickel $\left(\mathrm{Ni}^{2+}\right)$, ryanodine receptor antagonist ryanodine (Ryan), and store- operated channel/IP3 receptor blocker 2-APB. Wild-type control data are from second stimulation of control cells without added drug. Ratio values are normalized to the first stimulation before addition of drug and the error bars indicate standard error of mean. Single asterisk indicates significance $p<0.05$ and double asterisk $p \leq 0.01$, Dunnett's posthoc comparison. (D) Calcium transient amplitude in response to $100 \mathrm{mM} \mathrm{K} \mathrm{K}^{+}$after emptying intracellular stores with thapsigargin $(1 \mathrm{mM})$. Cells were incubated in bath solution for $10 \mathrm{~min}$ without (control) and with $1 \mathrm{mM}$ thapsigargin. No significant difference between control and drug was observed.

observed only at concentrations above $500 \mu M$ (Shtonda and Avery, 2005). To assess the involvement of L-type channels in the $1 \mathrm{~m} M$ nickel block, we tested the effects of three classes of L-type channel blockers, dihydropyridines (i.e., nifedipine), phenylalkamines (i.e., verapamil), and benzothiazepines (i.e., diltiazem), which bind reversibly to distinct, but overlapping sites in Ltype voltage-gated channels (Striessnig et al., 1998; Hockerman et al., 2000). Sequence comparisons between the rat brain $\alpha_{1}$ L-type calcium channel (Snutch et al., 1991) and the C. elegans L-type homologue EGL-19 indicated that the drug-binding residues for all three drug classes were present in EGL-19 as identical (14) or similar (four) residues [Fig. 3(B)]. We therefore expected all three classes of antagonist to block the invertebrate L-type calcium channel EGL-19. In contrast, alignment with the non-L-type channel UNC-2 showed only six identical residues, five similar, and seven nonsimilar residues, suggesting that UNC-2 channels would not be blocked by these inhibitors.

All three classes of L-type calcium channel blockers, diltiazem, nifedipine, and verapamil affected the cell's 

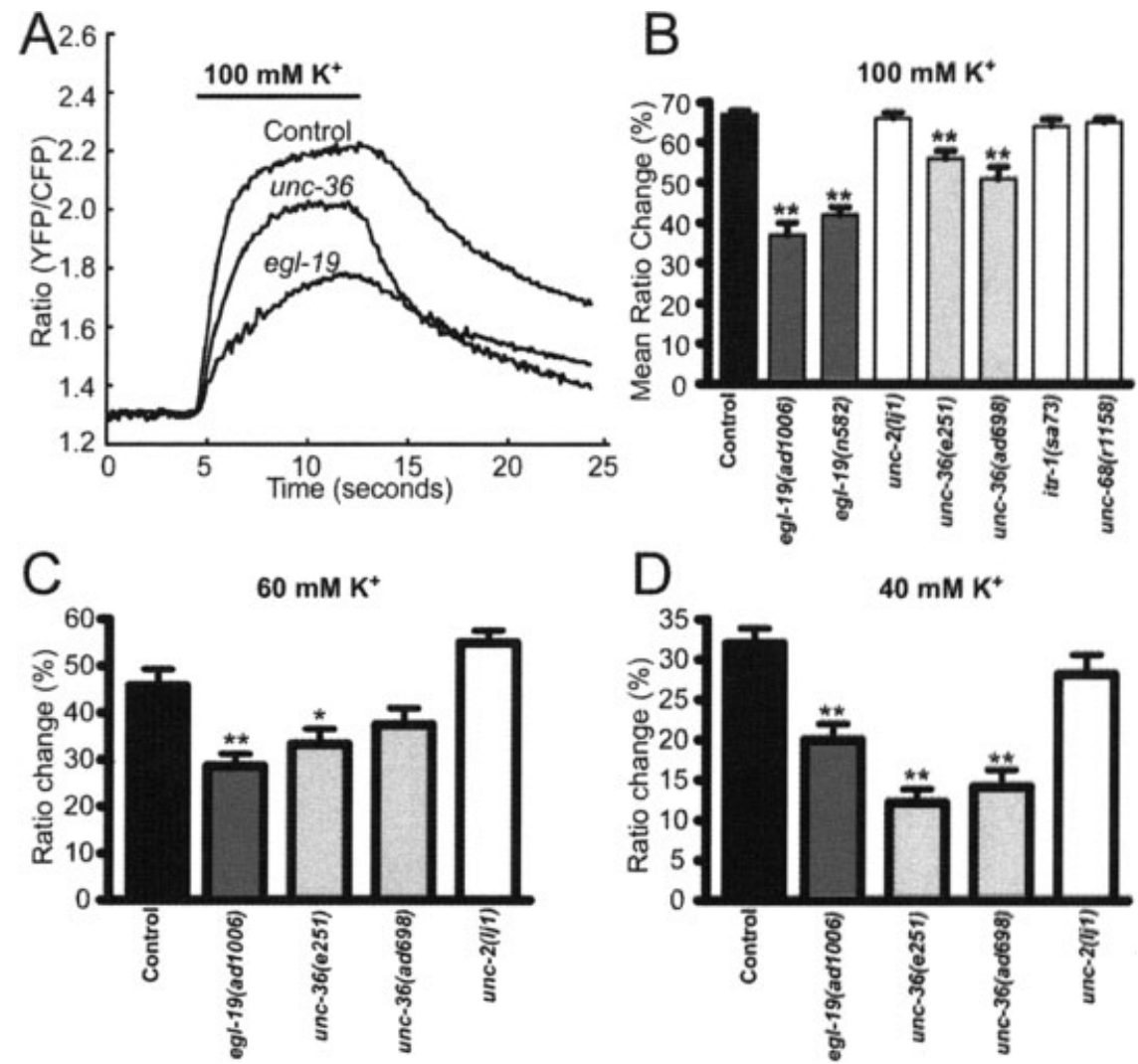

Figure 4 Mutant response to depolarization. (A) Representative averaged traces from wild-type, unc-36(e251), and egl-19(ad1006) responding to depolarization with $100 \mathrm{mM} \mathrm{K} \mathrm{K}^{+}$. Each trace is an average of one experiment with a number of neurons [wild-type 11 cells, unc-36(e251) eight cells, egl-19(ad1006) 15 cells]. The averaged traces have been normalized to a common prestimulation baseline for visual comparison. unc-36(e251) and egl-19(ad1006) both show a significant decrease in amplitude and a qualitative change in shape. (B) Wild-type and mutant response to $100 \mathrm{~m} M \mathrm{~K}^{+}$ depolarization. The plotted value for each mutant strain is the average response to the initial depolarization of the cells. Each plate with several cells is treated as one independent trial. egl-19 and unc-36 mutants have significant decreased transient amplitudes compared to control $(p<0.01)$. (C) Comparison of control, egl-19(ad1006), unc-36, and unc-2(lj1) response to depolarization with $60 \mathrm{mM} \mathrm{K} \mathrm{K}^{+}$. (D) Comparison of control, egl-19(ad1006), unc-36, and unc-2(lj1) response to depolarization with $40 \mathrm{mM} \mathrm{K} \mathrm{K}^{+}$. Only responsive cells were included in the analysis. All values are mean \pm standard error of mean. Statistical analysis was performed using Dunnett's posthoc test. Single asterisk $\left(^{*}\right)$ indicates statistical significance $p<0.05$ and double asterisk $(* *) p<0.01$ relative to control.

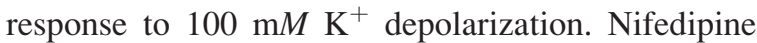
$(1 \mu M)$ and verapamil $(10 \mu M)$ significantly reduced the calcium transient amplitude. Diltiazem $(10 \mu M)$ did not significantly reduce the transient amplitude, although higher concentrations did (100 $\mu M$, not shown). However, this is in the range of unspecific pharmacological effects and could be due to nonspecific interactions with N- and P/Q-type channels (Dobrev et al., 1999). In comparison, $1 \mu M$ nifedipine reduced calcium currents by $50 \%$ in patch clamp recordings from the body wall muscle of dissected animals (Jospin et al., 2002). In the pharynx, higher concentrations of nifedipine $(10 \mu M)$ were necessary for reducing calcium currents, although even at this concentration the Ttype calcium current was unaffected (Shtonda and Avery, 2005). In our preparation higher concentrations of nifedipine $(10 \mu M)$ did not further reduce calcium transient amplitudes $[1 \mu M=45 \pm 3 \%(n=7)$ vs. $10 \mu M=40 \pm 2 \%(n=6), t$ test, $p>0.05$ ]. Consistent with recording from body wall muscle (Jospin et al., 2002) we did not see a potentiating effect of the vertebrate L-type channel agonist Bay K 8644 (up to $50 \mu M$, data not shown).

To further test the importance of L-type channels, we prepared neuronal cultures from loss-of-function mutant lines defective in the L-type channel gene egl- 
19. egl-19 null mutants are lethal but several partial loss-of-function alleles have been characterized (Lee et al., 1997). In addition, likely null alleles or reduction-of-function alleles are available for the non-Ltype voltage-gated channel gene unc-2 (Tam et al., 2000; Mathews et al., 2003), the ryanodine receptor gene unc-68 (Maryon et al., 1996), and the IP3 receptor gene itr-1 (Dal Santo et al., 1999). We generated cultures from each of these mutant lines and assayed the effect of each mutation on transient amplitude in response to depolarization (Fig. 4). We observed that egl-19 reduction-of-function mutants showed significantly reduced calcium influx in response to depolarization with extracellular potassium. In contrast, unc2(lj1), unc-68(rl158,) and itr-1(sa73) mutants showed neither any statistically significant reduction in mean ratio amplitude nor any apparent change in transient shape compared to wild-type [Fig. 4(B)]. These results provided further evidence that a major component of the depolarization-induced calcium transients in cultured touch neurons enters through EGL-19/L-type calcium channels.

SOC influx, or capacitative calcium influx, is a plasma membrane calcium current that is activated by the depletion of intracellular calcium stores (Putney, 2001). SOC influx is the major mechanism for calcium entry in nonexcitable cells and recent studies show that SOC influx also plays an important role in neurons (review Parekh and Putney, 2005). For example, capacitative activity-evoked calcium entry has been described in hippocampal pyramidal neurons (Baba et al., 2003). $\mathrm{Gd}^{3+}$ almost completely blocked transients and is an effective blocker of both VGCCs and SOCs. We used the blocker 2-APB, which predominantly blocks SOCs at low concentrations (tens of $\mu$ moles) as well as the IP3 receptor at higher concentrations (Bootman et al., 2002; Gregory et al., 2001; Baba et al., 2003) to assess the possible role of capacitative calcium influx in our observed calcium transients. In our preparation, application of 2-APB $(50 \mu M)$ significantly reduced the calcium transient amplitude. We coapplied 2-APB $(50 \mu M)$ and nifedipine $(1 \mu M)$ to test if the two compounds blocked distinct components of the calcium transient. Surprisingly, coapplication was not more effective at blocking calcium transients than nifedipine alone [Nif $(1 \mu M)=0.45 \pm 0.03 \%(n=7)$ vs. Nif $(1 \mu M)+2$ APB $(50 \mu M)=0.38 \pm 0.05 \%(n=7)$, unpaired $t$ test, $p>0.05$ ]. Because the pharmacological properties of 2-APB are not well-characterized in C. elegans it is possible that 2-APB and nifedipine block the same channel. Alternatively, the nifedipine-sensitive channel may be necessary for activating the 2-APBsensitive calcium flux. We also note that Estevez et al. (2005) have recently described a store-independent yet 2-APB- and lanthanum- sensitive outward rectifying calcium current in cultured epithelial intestinal cells, whose molecular identity is unknown.

We next tested for the involvement of intracellular stores with application of ryanodine, which at high concentrations $(20 \mu M)$ can completely and irreversibly block the ryanodine receptor in mammalian neurons without affecting calcium homeostasis (HernándezCruz et al., 1997). Consistent with normal transients in cultures from unc- 68 animals, application of ryanodine did not significantly change the transient amplitude [Fig. 3(C)]. As a complementary approach we incubated the cells for 10 min with thapsigargin $(1 \mu M)$ to empty intracellular stores before stimulation with $100 \mathrm{mM} \mathrm{K} \mathrm{K}^{+}$[Fig. 3(C)]. Depletion of intracellular stores also had no effect on calcium transients compared to control. In summary, a major portion of the calcium transients in our experiments appeared dependent on plasma membrane calcium flux through an L-type voltage gated channel. The difference between the unspecific divalent $\left(\mathrm{Ni}^{2+}\right)$ and trivalent $\left(\mathrm{Gd}^{3+}\right)$ cationic blockers and specific L-type blockers leaves open the possibility that other VGCCs (e.g., the T-type CCA-1 channel) also contribute to the calcium transients.

\section{UNC-36 $\alpha_{2} / \delta$ Subunit Is Expressed in Mechanosensory Neurons}

We next sought to determine the effect of the $\alpha_{2} / \delta$ subunit on these calcium transients. The $C$. elegans genome contains two sequences encoding proteins homologous to the VGCC $\alpha_{2} / \delta$ subunit, UNC-36 and T24F1.6. We used green fluorescent protein (GFP) promoter fusions to determine which of these proteins is expressed in the touch neurons. We generated transgenic lines expressing a fusion of $1.7 \mathrm{~kb}$ of UNC-36 upstream sequence to the coding region of GFP. We observed that this UNC-36::GFP reporter was expressed in most neurons and virtually all muscle tissue (consistently in body wall and vulval muscle, and sometimes in the pharyngeal muscle) (Fig. 5). We specifically identified expression of the UNC-36 reporter in mechanosensory neurons [Fig. 5(D,E)], as well as a number of additional unidentified neurons in the head and tail. Similarly, we made a GFP expression construct with $1.5 \mathrm{~kb}$ of the T24F1.6 promoter. Expression was seen in the gut [Fig. 5(F-I)] as well as in a small number of head and tail neurons. We did not detect GFP expression in touch neurons. Our expression data suggested that UNC-36 is the primary $\alpha_{2} / \delta$ subunit for neuronal and muscle cell VGCCs. 

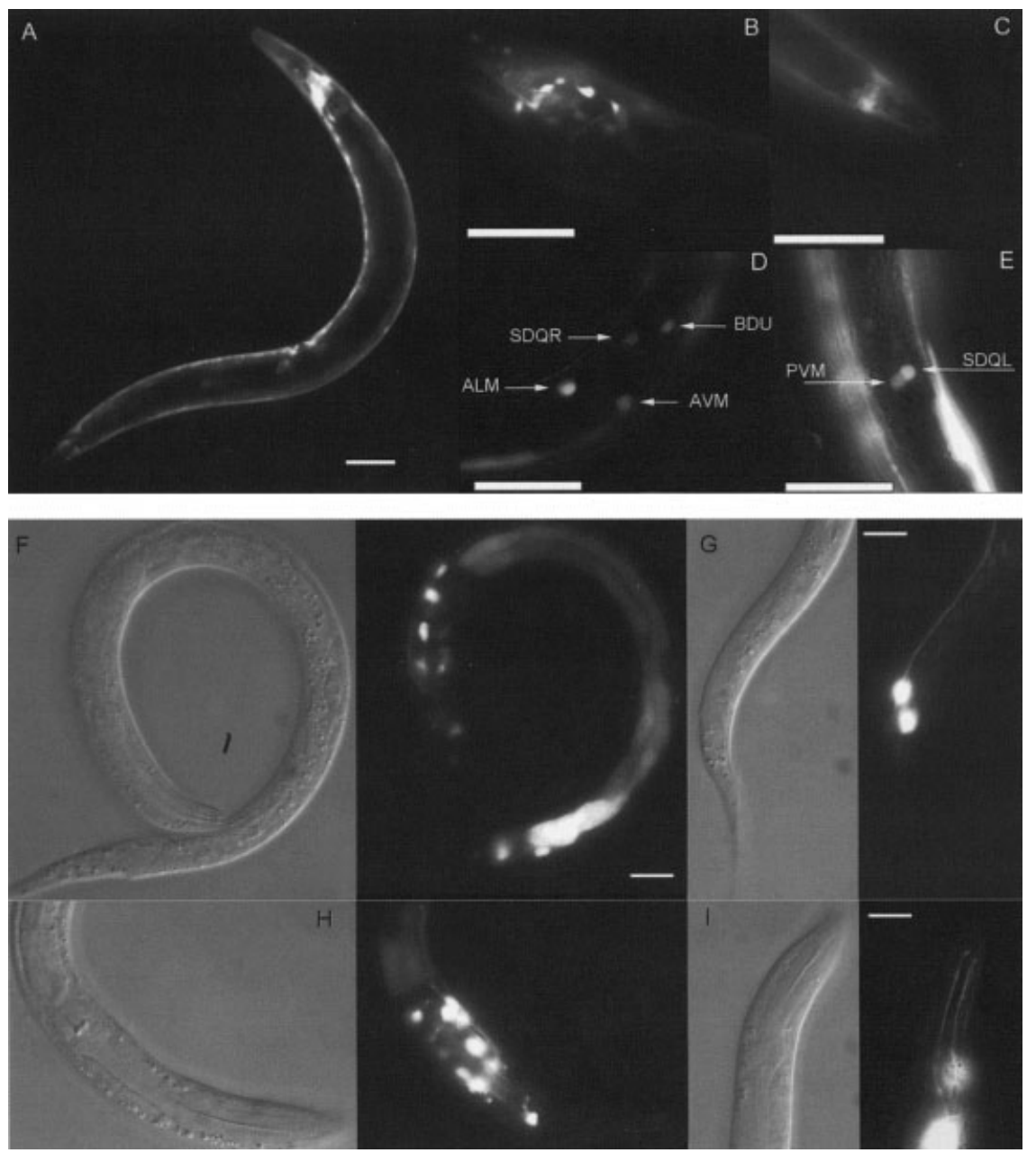

Figure 5 UNC-36 and T24F1.6 expression patterns. (A) Expression construct pUNC-36::GFP was made by fusing a $1.7 \mathrm{~kb}$ upstream region of UNC-36 to GFP. Whole worm image shows expression in both muscle and neurons. (B) Magnification showing expression in the nerve ring. (C) Tail expression. (D) Worms in the L2 stage were scored for expression in the mechanosensory neurons by Nomarski. Fluorescence was positively located to AVM, ALM, and PVM. Arrows indicate GFP expression in ALM, AVM, BDU, and SDQR. We also identified GFP expression in the tail neurons PVQ, PVC, DUC, and DVA. PLM, ALN, and PHB were probable, but not certain, because these neurons are particularly difficult to identify. In the head GFP was expressed in ASE, AVA, SIBDL, RMDVL, ASK, and a number of unidentified neurons. (E) Expression in PVM and SDQL. (F) Expression construct pT24F1.6::GFP was made by fusing a $1.5 \mathrm{~kb}$ upstream region of T24F1.6 to GFP. Expression is seen in a small number of neurons and in the gut. AVM, ALM, and PVM were identified by DIC microscopy and no GFP expression could be seen in these cells.

(G) Tail. (H) Head. (I) Amphid neurons in head. All scale bars $=50 \mu \mathrm{m}$.

\section{UNC-36 Loss-of-Function Mutations Decrease Calcium Transient Amplitudes}

Because UNC-36 was the only $\alpha_{2} / \delta$ subunit whose expression was detected in the touch receptor neurons, we investigated the effect of unc-36 mutations on calcium transients in these cells. We prepared cultures from unc-36(e251) and unc-36(ad698) embryos, which carry severe loss-of-function mutations, and examined the responses of these cells to depolariza- tions with 40, 60, and $100 \mathrm{mM} \mathrm{K} \mathrm{K}^{+}$. As shown in Figure 4(B), unc-36 mutant cells showed a significant, but relatively small, reduction in the ratio change amplitude in response to depolarization with $100 \mathrm{mM}$ $\mathrm{K}^{+}$. Interestingly, this reduction in response amplitude relative to wild-type was more pronounced when the cells were stimulated with 40 or $60 \mathrm{mM} \mathrm{K}{ }^{+}$[Fig. $4(\mathrm{C}, \mathrm{D})]$. Thus, mutations in the $\alpha_{2} / \delta$ subunit gene unc-36, like mutations in the $\alpha_{1}$ subunit gene egl-19, reduced the overall magnitude of the calcium transient 
induced by depolarization. Furthermore, unc-36 mutations also had the additional effect of decreasing the neurons' sensitivity to smaller depolarizing stimuli. We also tested the effect of the putative mammalian $\alpha_{2} / \delta$-specific blocker gabapentin on calcium transients (Gee et al., 1996; Marais et al., 2001), although the C. elegans UNC-36 $\alpha_{2} / \delta$ subunit lacks several residues that are necessary for gabapentin binding to mammalian $\alpha_{2} / \delta$ subunits (Wang et al., 1999). Consistent with this we could not detect any significant effect of gabapentin on calcium transients (data not shown).

\section{Effects of unc-36 on Calcium-Dependent Processes in the Touch Neurons In Vivo}

To further investigate the effect of unc-36 on neuronal calcium transients, we analyzed the effects of unc-36 mutations on in vivo neuronal calcium transients and behavioral responses. To investigate responses to touch stimuli, cameleon-expressing wild-type and unc-36 mutant lines were immobilized on agarose pads, and mechanical stimuli were applied using an automated stimulus generator (Suzuki et al., 2003). Although we had earlier detected reduced calcium transients in egl-19 animals (Suzuki et al., 2003), we were not able to detect any statistical difference between the ratio changes evoked by mechanical stimuli in unc-36 mutants and controls. However, we also assayed unc36 mutants for defects in touch avoidance behavior. Surprisingly, unc-36 mutant animals were more strongly touch-insensitive than egl-19 mutants. In a standard gentle touch assay using an eyelash, unc-36 null animals responded only $49 \%$ of the time, whereas the strongest egl-19 reduction-of-function mutant responded to this stimulus $71 \%$ of the time (wild-type animals responded $81 \%$ of the time). This indicates that despite the stronger effect of egl-19 on cell body calcium transients, unc-36 has other roles in the touch neurons or elsewhere in the touch response circuit that are critical for touch avoidance. Interestingly, we observed that animals carrying null alleles of the non-Ltype VGCC $\alpha_{1}$ subunit gene unc-2, which did not affect cell body calcium transients in the touch neurons (Suzuki et al., 2003) or cultured neurons [Fig. 4(B)], were also strongly touch-insensitive. unc-2 loss-offunction mutants showed only a $28 \%$ response frequency in the eyelash assay, a touch avoidance defect nearly as strong as that observed in animals in which the touch neurons are absent [mec-4(u231d); $16 \%$ response]. These results suggest that the touch response phenotype of unc-36 mutants could be a result of UNC-36 functioning as an auxiliary subunit of UNC-2 calcium channels, either in the touch neurons themselves or elsewhere in the touch avoidance circuit.

To further assess this possibility, we analyzed the effect of unc-36 mutations on the cell migrations of
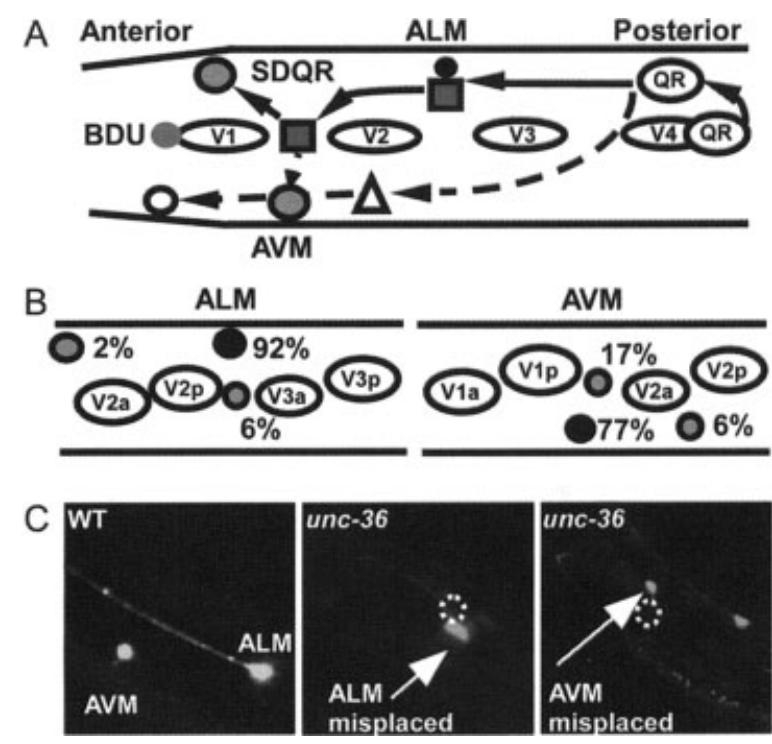

Figure 6 Migration defects of unc-36 animals. (A) Postembryonic migrations of the $\mathrm{Q}$ descendant neurons. After AVM and SDQR (filled circles) arise from division of QR.pa (filled squares), SDQR migrates dorsally and anteriorly and projects an axon into the sublateral nerve. AVM migrates ventrally and projects an axon into the ventral nerve cord. (B) The final positions of ALM and AVM in unc-36(e251) mutants are summarized. The positions of the cell body were scored in relation to the epidermal cells V2.a, V2.p, V3.a, and V3.p (see Methods). The normal positions of the ALM and AVM nuclei are indicated by the black circles; aberrant positions are indicated by the gray filled circles. The percentages of nuclei at each position are indicated next to the appropriate circle. (C) Representative images of wildtype (left) and unc-36 mutants (middle and right) expressing pmec-4::GFP. In all images, right is posterior and top is dorsal. The normal positions of ALM (middle) and AVM (right), as determined by Nomarski optics, are circled.

the touch neuron cell bodies during development, a process shown previously to depend on the cell-autonomous activity of UNC-2 in the developing touch neurons (Fig. 6). unc-2 null mutants were shown previously to have cell migration defects resulting in misplacement of the AVM and ALM cell bodies with 34 and $41 \%$ penetrance, respectively (Kindt et al., 2002). In contrast, egl-19 reduction-of-function mutations affected guidance of the AVM axon [20\% penetrant defect in egl-19(adl006)], and, to a lesser extent, the migration of the AVM cell body (penetrance ranged from $6-16 \%$ for different alleles; Tam et al., 2000). When we analyzed unc-36 mutant animals, we observed a significant AVM cell migration phenotype (23\% penetrance) as well as lower penetrance ALM cell migration (8\%) and axon guidance (6\%) phenotype (Fig. 6). Though the low penetrance of these defects makes them unlikely to account for 
the behavioral defects in touch response, they are consistent with a functional role for the UNC-36 protein in the activity of UNC-2 and EGL-19 calcium channels during development of the touch neurons.

\section{DISCUSSION}

We have shown here that the calcium channel genes egl-19 and unc-36 play important roles in regulating depolarization-induced calcium influx in $C$. elegans mechanosensory neurons. The L-type homologue EGL-19 was shown previously to be the main VGCC responsible for depolarization and calcium influx in pharyngeal muscle (Lee et al., 1997; Kerr et al., 2000; Shtonda and Avery, 2005) as well as body wall muscle (Jospin et al., 2002). The results presented here suggest a key role for L-type calcium channels in the excitability of cell bodies of $C$. elegans mechanosensory neurons. Together with the observations that transients are not observed in the absence of extracellular calcium and are reduced by egl-19 mutations, we conclude that $\mathrm{Ca}^{2+}$ influx through the L-type VGCC EGL-19 is important for generating transients in the cell body in response to depolarization. The reduced transient amplitude in egl-19(ad1006) loss-of-function mutants stimulated in vivo by gentle touch stimulation (Suzuki et al., 2003) further supports this hypothesis.

In contrast, mutations in the non-L-type HVA channel UNC-2 did not measurably affect the calcium transients observed in the touch neuron cell bodies. However, behavioral data are consistent with the possibility that these channels contribute to touch neuron calcium transients under other conditions or in cellular compartments other than the cell body. For example, previous studies (Tam et al., 2000) showed that UNC-2 is important for directing touch neuron cell migrations. In addition, because unc- 2 mutations appear to confer defects in synaptic vesicle release from motorneurons, it is possible that UNC-2 channels might mediate localized calcium influx at presynaptic regions, while EGL-19 channels mediate calcium influx more generally at neuronal cell bodies and processes. Because we record calcium transients in the cell body it is likely that we would not pick up changes in local calcium transients at the synapse. The fact that unc-2 loss-of-function mutants show marked behavioral deficits in touch avoidance behavior is consistent with this possibility, though this phenotype could also be explained by a function of UNC-2 channels elsewhere in the touch avoidance circuit.

Neither ryanodine nor a putative null mutant in the only $C$. elegans ryanodine receptor gene unc-68 (Maryon et al., 1996) detectably altered calcium transients in our assays. Also, depleting intracellular stores with thapsigargin did not reduce calcium transients. Nonetheless, unc-68 mutations, as well as mutations in the IP3 receptor gene itr- 1 and the calreticulin gene crt- 1 have been shown to function in the touch neurons to promote necrotic cell death induced by dominant alleles of the MEC-4 mechanosensory channel (Xu et al., 2001). Thus, intracellular calcium release may contribute to touch neuron calcium transients under conditions other than those used in our assays. Likewise, it is possible that other channels, for example an unidentified TRP or DEG/ENaC channel, could also contribute to touch neuron calcium transients in vivo.

These studies also demonstrate a role for the $\alpha_{2} / \delta$ subunit UNC-36 in mechanosensory neurons. unc-36 loss-of-function mutants significantly decrease calcium transient amplitudes in cultured neurons depolarized with potassium. Because at least a large component of this cell body calcium transient is dependent on the flux through EGL-19 channels, it appears likely that UNC-36 functions as an accessory subunit that positively regulates the activity of touch neuron EGL-19 channels. Interestingly, the effect of UNC36 on calcium influx appears most pronounced when weaker depolarizing stimuli are used; thus, the UNC$36 \alpha_{2} / \delta$ subunit may affect the voltage sensitivity of the channel(s). These results are also consistent with the possibility that some of the unc-36 effect on calcium influx could represent effects on other voltagegated channels, such as a T-type channel that might mediate the nifedipine-insensitive component of the calcium transients. In fact, other touch-related phenotypes of unc-36 imply that it may encode an accessory subunit of UNC-2 calcium channels in the touch neurons. For example, both the Mec (touch-insensitive) and Mig (cell migration) phenotypes of unc-36 parallel similar phenotypes observed for unc-2 mutants, suggesting that the activity of UNC-2 channels might be impaired in unc-36 animals.

In summary, we have used calcium imaging on cultured neurons, combined with genetics and pharmacology, to gain new information about the molecular mechanisms that control calcium entry in $C$. elegans mechanosensory neurons. In support of previous findings, our data indicate that the calcium channels containing the EGL-19 $\alpha-1$ subunit provide a major component of the voltage-dependent calcium transients in the touch neuron cell body. These channels show strong similarities, based on pharmacological criteria, with vertebrate L-type VGCCs. UNC-36 appears to function as an accessory subunit of these channels that may enhance current amplitude as well as voltage sensitivity. In addition, UNC-36 may play a similar role in association with UNC-2 channels that promote cell migration and possibly synaptic ac- 
tivity in mechanosensory neurons. More generally, we have shown that cultured mechanosensory neurons expressing the genetically encoded cameleon YC2.12 can be used as a robust experimental system, and that the response properties of YC2.12, which has been used for a number of in vivo studies in $C$. elegans (Suzuki et al., 2003; Shyn et al., 2003; Bianchi et al., 2004; Kimura et al., 2004; Hilliard et al., 2005), are robust against variability in expression levels and baseline YFP/CFP ratio. Thus, calcium imaging studies using these genetically encoded calcium indicators should have many future applications for the characterization of neuronal physiology in C. elegans.

The authors would like to thank Laura Bianchi for sharing advice and unpublished data on cultured mechanosensory neurons, Massimo Hilliard for help scoring GFP expression patterns, Oliver Hobert for help with overlap PCR, and the Caenohrabditis Genetics Center for strains. C.F.J. was funded by Psykiatrisk Forskningsfond, Novo Nordisk Foundation, and Eva og Robert Voss Hansen Foundation. R.A.K. was supported by an NIH postdoctoral training grant. K.S.K. was supported by a Kirschstein Predoctoral Fellowship from the NIH.

\section{REFERENCES}

Baba A, Yasui T, Fujisawa S, Yamada RX, Yamada MK, Nishiyama N, Matsuki N, et al. 2003. Activity-Evoked Capacitative $\mathrm{Ca} 2+$ Entry: Implications in Synaptic Plasticity. J Neurosci 23:7737-7741.

Biagi BA, Enyeart JJ. 1990. Gadolinium blocks low- and high-threshold calcium currents in pituitary cells. Am J Physiol 259:C515-520.

Bianchi L, Gerstbrein B, Frøkjær-Jensen C, Royal DC, Mukherjee G, Royal MA, Xue J, et al. 2004. The neurotoxic MEC-4(d) DEG/ENaC sodium channel conducts calcium: implications for necrosis initiation. Nat Neurosci 7:1337-1344.

Bleakman D, Bowman D, Bath CP, Brust PF, Johnson EC, Deal CR, Miller RJ, et al. 1995. Characteristics of a Human N-type Calcium Channel Expressed in HEK293 Cells. Neuropharmacology 34:753-765.

Bootman MD, Collins TJ, MacKenzie L, Roderick HL, Berridge MJ, Peppiatt CM. 2002. 2-Aminoethozydiphenyl borate (2-APB) is a reliable blocker of store-operated $\mathrm{Ca} 2+$ entry but an inconsistent inhibitor of InsP3induced $\mathrm{Ca} 2+$ release. FASEB 16:1145-1150.

Catterall WA. 2000. Structure and regulation of voltage-gated $\mathrm{Ca}^{2+}$ channels. Annu Rev Cell Dev Biol 16:521-555.

Christensen M, Estevez A, Yin X, Fox R, Morrison R, McDonnell M, Gleason C, et al. 2002. A primary culture system for functional analysis of $\mathrm{C}$. elegans neurons and muscle cells. Neuron 33:503-514.

Dal Santo P, Logan MA, Chisholm AD, Jorgensen EM. 1999. The inositol trisphosphate receptor regulates a 50-second behavioral rhythm in C. elegans. Cell 98:757-767.
Dobrev D, Milde AS, Andreas K, Ravens U. 1999. The effects of verapamil and diltiazem on N-, P- and Q-type calcium channels mediating dopamine release in rat striatum. Br J Pharmacol 127:576-582.

Ertel SI, Ertel EA, Clozel JP. 1997. T-type Ca2+ channels and pharmacological Blockade: Potential Pathophysiological Relevance. Cardiovasc Drugs Ther 11:723-739.

Estevez AY, Roberts RK, Strange K. 2005. Identification of Store-independent and Store-operated $\mathrm{Ca} 2+$ conductances in Caenorhabditis elegans Intestinal Epithelial Cells. J Gen Physiol 122:207-223.

Evanko DS, Haydon PG. 2005. Elimination of environmental sensitivity in a cameleon FRET-based calcium sensor via replacement of the acceptor with Venus. Cell Calcium 37:341-348.

Gee NS, Brown JP, Dissanayake VU, Offord J, Thurlow R, Woodruff GN. 1996. The novel anticonvulsant drug, gabapentin (Neurontin), binds to the alpha2delta subunit of a calcium channel. J Biol Chem 271:5768-5776.

Goodman MB, Hall DH, Avery L, Lockery SR. 1998. Active Currents Regulate Sensitivity and Dynamic Range in C. elegans Neurons. Neuron 20:763-772.

Gregory RB, Rychkov G, Barritt GJ. 2001. Evidence that 2aminoethyl dephenylborate is a novel inhibitor of storeoperated $\mathrm{Ca} 2+$ channels in liver cells, and acts through a mechanism which does not involve inositol triphosphate receptors. Biochem J 354:285-290.

Hernández-Cruz A, Escobar AL, Jiménez N. 1997. Ca ${ }^{2+}$ induced $\mathrm{Ca}^{2+}$ Release Phenomena in Mammalian Sympathetic Neurons Are Critically Dependent on the Rate of Rise of Trigger $\mathrm{Ca}^{2+}$. J Gen Phys 109:147-167.

Hille B. 2001. Ionic Channels of Excitable Membranes, 3rd Ed. Sunderland, MA: Sinauer, 814 p.

Hilliard MA, Apicella AJ, Kerr R, Suzuki H, Bazzicalupo P, Schafer WR. 2005. In vivo imaging of C. elegans ASH neurons: cellular responses and adaptation to chemical repellents. EMBO J 24:63-72.

Hobert O. 2002. PCR fusion-based approach to create reporter gene constructs for expression analysis in transgenic C. elegans. Biotechniques 32:728-730.

Hockerman GH, Dilmac N, Scheuer T, Catterall WA. 2000. Molecular Determinants of Diltiazem Block in Domains IIIS6 and IVS6 of L-type $\mathrm{Ca}^{2+}$ channels. Mol Pharmacol 58:1264-1270.

Jay SD, Sharp AH, Kahl SD, Vedvick TS, Harpold MM, Campbell KP. 1991. Structural characterization of the dihydropyridine-sensitive calcium channel alpha 2-subunit and the associated delta peptides. J Biol Chem 15:3287-3293.

Jospin M, Jacquemond V, Mariol MC, Segalat L, Allard B. 2002. The L-type voltage-dependent $\mathrm{Ca} 2+$ channel EGL-19 controls body wall muscle function in Caenorhabditis elegans. J Cell Biol 159:337-348.

Kerr R, Lev-Ram V, Baird G, Vincent P, Tsien RY, Schafer WR. 2000. Optical imaging of calcium transients in neurons and pharyngeal muscle of C. elegans. Neuron 26:583-594.

Kimitsuki T, Nakagawa T, Hisashi K, Komune S, Komiyama S. 1996. Gadonolinium blocks mechano-electric transducer current in chick cochlear hair cells. Hearing Res 101:75-80. 
Kimura KD, Miyawaki A, Matsumoto K, Mori I. 2004. The C. elegans Thermosensory Neuron AFD Responds to Warming. Curr Biol 14:1291-1295.

Kindt KS, Tam T, Whiteman S, Schafer WR. 2002. Serotonin promotes $\mathrm{G}(\mathrm{o})$-dependent neuronal migration in Caenorhabditis elegans. Curr Biol 12:1738-1747.

Klugbauer N, Marais E, Hofmann F. 2003. Calcium channel alpha2delta subunits: Differential Expression, Function, and Drug binding. J Bioenerg Biomembr 35:639-647.

Lee JH, Gomora JC, Cribbs LL, Perez-Reyes E. 1999. Nickel Block of Three Cloned T-type Calcium Channels: Low Concentrations Selectively Block alpha1H. Biophys J 77:3034-3042.

Lee RYN, Lobel L, Hengartner M, Horvitz HR, Avery L. 1997. Mutations in the alpha1 subunit of an L-type voltage-activated $\mathrm{Ca}^{2+}$ channel cause myotonia in Caenorhabditis elegans. EMBO 16:6066-6076.

Letts VA, Felix R, Biddlecome GH, Arikkath J, Mahaffey CL, Valenzuela A, Bartlett FS 2nd, et al. 1998. The mouse stargazer gene encodes a neuronal $\mathrm{Ca}^{2+}$-channel gamma subunit. Nat Genet 19:340-347.

Marais E, Klugbauer N, Hofmann F. 2001. Calcium Channel $\alpha_{2} / \delta$ subunits - Structure and Gabapentin Binding. Mol Pharmacol 59:1243-1248.

Martin DJ, McClelland D, Herd MB, Sutton KG, Hall MD, Lee K, Pinnock RD, et al. 2001. Gabapentin-mediated inhibition of voltage-activated $\mathrm{Ca} 2+$ channel currents in cultured sensory neurones is dependent on culture conditions and channel subunit expression. Neuropharmacology 42:353-366.

Maryon EB, Coronado R, Anderson P. 1996. Unc-68 Encodes a Ryanodine Receptor Involved in Regulating C. elegans Body-Wall Muscle Contraction. J Cell Biol 134:885-893.

Mathews EA, Garcia E, Santi CM, Mullen GP, Thacker C, Moerman DG, Snutch TP. 2003. Critical residues of the Caenorhabditis elegans unc-2 voltage-gated calcium channel that affect behavioral and physiological properties. J Neurosci 23:6537-6545.

Mello C, Fire A. 1995. DNA transformation. In: Epstein HF, Shakes DC, editors. Caenorhabditis elegans: Modern Biological Analysis of an Organism, Methods in Cell Biology, Volume 48. San Diego, CA: Academic Press, pp. 451-482.

Miyawaki A, Griesbeck O, Heim R, Tsien RY. 1999. Dynamic and quantitative $\mathrm{Ca} 2+$ measurements using improved cameleons. Proc Natl Acad Sci USA 96:21352140.

O'Hagan R, Chalfie M, Goodman MB. 2004. The MEC-4 $\mathrm{DEG} / \mathrm{ENaC}$ channel of Caenorhabditis elegans touch receptor neurons transduces mechanical signals. Nature Neurosci 8:43-50.

Parekh AB, Putney JW Jr. 2005. Store-operated calcium channels. Physiol Rev 85:757-810.

Putney JW Jr. 2001. The Pharmacology of capacitative calcium entry. Mol Interventions 1:84-94.

Reiff DF, Ihring A, Guerrero G, Isacoff EY, Joesch M, Nakai J, Borst A. 2005. In vivo performance of genetically encoded indicators of neural activity in flies. J Neurosci 25:4766-4778.
Sárközi S, Szegedi C, Lukács B, Ronjat M, Jóna I. 2005. Effect of gadolinium on the ryanodine receptor/sarcoplasmatic reticulum calcium release channel of skeletal muscle. FEBS J 272:464-471.

Schafer WR, Kenyon CJ. 1995. A calcium-channel homologue required for adaptation to dopamine and serotonin in Caenorhabditis elegans. Nature 375:73-78.

Shtonda B, Avery L. 2005. CCA-1, EGL-19 and EXP-2 currents shape action potentials in Caenorhabditis elegans pharynx. J Exp Biol 208:2177-2190.

Shyn SI, Kerr R, Schafer WR. 2003. Serotonin and Go modulate functional states of neurons and muscles controlling C. elegans egg-laying behavior. Curr Biol 13: 1910-1915.

Singer D, Biel M, Lotan I, Flockerzi V, Hofmann F, Dascal N. 1991. The roles of the subunits in the function of the calcium channel. Science 253:1553-1557.

Snutch TP, Tomlinson WJ, Leonard JP, Gilbert MM. 1991. Distinct calcium channels are generated by alternative splicing and are differentially expressed in the mammalian CNS. Neuron 7:45-57.

Steger KA, Shtonda BB, Thacker C, Snutch TP, Avery L. 2005. The C. elegans T-type calcium channel CCA-1 boosts neuromuscular transmission. J Exp Biol 208:2191-2203.

Striessnig J, Grabner M, Mitterdorfer J, Hering S, Sinnegger MJ, Glossman H. 1998. Structural basis of drug binding to L Ca2+ channels. Trends Pharm Sci 19:108-115.

Sutton KG, Martin DJ, Pinnock RD, Lee K, Scott RH. 2002. Gabapentin inhibits high-threshold calcium channel currents in cultured rat dorsal root ganglion neurones. Br J Pharmacology 135:257-265.

Suzuki H, Kerr R, Bianchi L, Frøkjær-Jensen C, Slone D, Xue J, Gerstbrein B, et al. 2003. In vivo imaging of C. elegans mechanosensory neurons demonstrate a specific role for the MEC-4 channel in the process of gentle touch sensation. Neuron 39:1005-1017.

Tam T, Mathews E, Snutch TP, Schafer WR. 2000. Voltage-Gated Calcium Channels Direct Neuronal Migration in Caenorhabditis elegans. Dev Biol 226:104-117.

Thomas JH, Lockery S. 1999. Neurobiology. In: C. elegans: a Practical Approach, ed. I. Hope, Oxford University Press.

Truong K, Sawano A, Mizuno H, Hama H, Tong KI, Mal TK, Miyawaki A, et al. 2001. FRET-based in vivo Ca2+ imaging by a new calmodulin-GFP fusion molecule. Nat Struct Biol 8:1069-1073.

Wang M, Offord J, Oxender DL, Su T-Z. 1999. Structural requirement of the calcium-channel subunit $\alpha_{2} \delta$ for gabapentin binding. Biochem J 342:313-320.

$\mathrm{Xu} \mathrm{K}$, Tavernarakis N, Driscoll M. 2001. Necrotic cell death in $\mathrm{C}$. elegans requires the function of calreticulin and regulators of $\mathrm{Ca} 2+$ release from the endoplasmic reticulum. Neuron 31:957-971.

Yang X-C, Sachs F. 1989. Block of Stretch-Activated Ion Channels in Xenopus Oocytes by Gadolinium and Calcium ions. Science 243:1068-1071.

Zamponi GW, Bourinet E, Snutch TP. 1996. Nickel Block of a Family of Neuronal Calcium Channels: Subtypeand Subunit-Dependent Action at Multiple Sites. J Membr Biol 151:77-90. 